\title{
A management dilemma: Positioning employees for internal competition versus internal collaboration. Is coopetition possible?
}

\author{
S. Naidoo and M. Sutherland* \\ Gordon Institute of Business Science, University of Pretoria, South Africa \\ *To whom all correspondence should be addressed \\ sutherlandm@gibs.co.za
}

\begin{abstract}
Managers are faced with the dilemma of either positioning their employees to compete against or to collaborate with each other within the organisation. Internal competition can motivate individuals and teams to strive to be the best and in so doing result in continuous incremental performance improvements. In contrast, internal collaboration can result in effective problem solving through knowledge sharing and innovation. This study investigated the key factors that drive the adoption of internal competition and internal collaboration, the consequences of implementing each approach, how levels of internal competition and internal collaboration vary at different management levels and whether a viable hybrid combination of both management approaches is possible. A qualitative exploratory study by in-depth interview was conducted with twenty senior executives. A hybrid model was developed from these research findings, which confirms that while the two management approaches have different outcomes there is an optimal way of combining them to allow managers to optimise the performance of their staff and the organisation.
\end{abstract}

\section{Introduction}

In order to remain competitive companies, in an increasingly complex business environment, need to differentiate themselves from their competitors. One key differentiating characteristic of a successful company has been identified as management's ability to effectively manage dilemmas and paradox (Yoon \& Chae, 2012). Hulsmann and Berry (2004) argue that as a result of changing conditions, managers find that they are often faced with situations, where a single strategic alternative no longer fulfils their needs. Many managers grapple with the dilemma of which management approach to adopt in order to drive sustainable peak organisational performance (Lusher \& Lewis, 2008). Such tensions are inherent and persistent within high performing organisations and it is management's deliberate and purposeful response to these paradoxical tensions that will ensure organizational performance over time (Lusher \& Lewis, 2008; Smith \& Lewis, 2011). Gilbert and Sutherland (2013) argue that a combination of seemingly contradictory strategic alternatives could be used advantageously to set an organisation apart from its competitors. This research focuses on the dilemma of two seemingly contradictory management approaches; the tension between internal competition versus internal collaboration.

In his seminal study on social interdependence, Deutsch (1949) defined a collaborative group structure as one where a gain by one group member contributes to the gain of the other group members and where rewards are shared equally. He defines a competitive group structure as one where the gain of one group member reduces the gain that can be obtained by the other group members, and where rewards are shared unequally. Robbins, Judge, Odendaal and Roodt (2009) build on these definitions by describing collaboration as the attempt to find a win/win solution that allows both parties' goals to be completely achieved. They define competition as simply seeking to satisfy one's own interests, regardless of the impact of others. Deutch (1949) found that competition or collaboration can occur between individuals, within a group (intragroup) and between groups (intergroup). Tsai (2002:179) stated, “In today's multiunit organizations, many units are forced to both compete and collaborate with each other. This paradox has become a major challenge." This study focuses specifically on competition and collaboration internal to an organization, between individuals within teams, between teams and between operational business units.

DuBois (2012) looked at practical examples of this dilemma. First of all looking at the internationally well-known competitive environment of law and consulting companies where new graduate recruits compete over a number of years for the few partner vacancies that occur each year leading to the well know practice of "up or out". She then goes on to compare Jack Welch's at GE highly debated forced ranking of all employees where the lowest performing $10 \%$ were expected to exit the company each year, to Pepsico's alternate approach where $40 \%$ of one's bonus depends on demonstrated evidence of collaborative behavior. Finally she mentions the Wharton study where employees ranked below average in a competitive environment remain less productive in future cycles - the ranking system being shown to not motivate the poor performer.

While research exists on focused aspects of competition and collaboration internally between an organisation's business units and teams (Deutsch, 1949; Birkinshaw, 2001; Houston, Walker, Hutt \& Reingen, 2001; Tsai, 2002; Luo, Slotegraaf \& Pan, 2006) as well as externally between multiple organisations (Nalebuff \& Brandenburger, 1996; Bengtsson 
\& Kock, 2000; Rijamampianina \& Carmichael, 2005), there is no consensus on how to manage the dilemma or how to achieve the right balance between internal competition and internal collaboration broadly within an organisation. Coopetition, the use of both competition and cooperation in various phases or in various aspects has been suggested by some as a solution (Tsai, 2002; Luo, Slotegraf and Pan, 2006).

It thus becomes a management quandary as to which combination of approaches is the most effective for a given situation (Gilbert \& Sutherland, 2013). The objectives of this study are to identify the key factors that drive the adoption of internal competition and internal collaboration within organisations, assess the positive and negative outcomes that can result from the two approaches and investigate whether the use of internal collaboration and internal competition varies between executive and non-executive levels. Finally this study seeks to establish if it is possible internally in organisations for collaborative and competitive management approaches to co-exist and how such hybrids, sometimes referred to as coopetition (Tsia, 2002; Luo et al., 2006), could be enacted to achieve high levels of sustainable organisational performance.

\section{Literature review}

\section{Management dilemmas and paradox}

Managers are often faced with a decision that contains the "horns of a dilemma" (Peters, 2012) where managers must make a choice between two seemingly opposing but reasonable alternatives, each with positive and negative consequences (Hulsmann \& Berry, 2004; Serreta, Bendixen \& Sutherland, 2009; Smith \& Lewis, 2011; Johnson, 2012; Yoon \& Chae, 2012). These choices are generally presented in either/or terms, with either choice being able to be reasonably defended (Peters, 2012; Johnson 2012). Often these management dilemmas are inherently paradoxical in nature, where the two states are seemingly contradictory. Examples of such dilemmas include exploitation and exploration (Andriopoulos \& Lewis, 2009), employee autonomy and management control (Gilbert \& Sutherland, 2013), organisational stability and change (Farjoun, 2010; Nasim \& Sushil, 2011) and collaborating with competitors (Rijamampianina \& Carmichael, 2005; Chin, Chan \& Lam, 2008). Serreta et al. (2009), Johnson (2012) and Peters (2012) show that dilemmas are typically defined as two extreme options which imply conflicting gains. Hulsmann and Berry (2004) contend that management dilemmas are often based on situations where there are opposing rules for measuring achievement within the organisation. Smith and Lewis (2011) explain that as each horn of the dilemma represents a different set of costs and benefits, the decision will result in a trade-off with possibly unintended consequences.

Paradoxes have been defined as contradictory yet interrelated options that can exist simultaneously and continue over time (Smith \& Lewis, 2011; Johnson, 2012; Yoon \& Chae, 2012). Paradoxes are made up of elements that seem logical individually but inconsistent when considered together.
Kahane (2010) argues that the challenge is not in choosing one option but rather in managing the inherent tension and achieving a measure of balance between the two forces. However balance between paradoxical options may only be temporary since the inherent tension between the contradictory elements will resurface (Smith \& Lewis, 2011; Gilbert \& Sutherland, 2013; Johnson 2012). As globalisation, innovation, competition and social pressures produce increasingly complicated environments, paradox becomes a powerful lens for understanding and managing organisational tensions (Smith \& Lewis, 2011). Purposeful responses to management paradoxes and dilemmas can enable sustainability and increased levels of performance (Serretta et al., 2009; Johnson, 2012, Smith \& Lewis, 2011). Various authors discuss the importance of bridging the horns of a dilemma and moving from the perspective of an either/or approach to a both/and approach (Kahane, 2012; Peters, 2012; Yoon \& Chae, 2012 and Smith \& Lewis, 2011).

The management dilemma of choosing between internal competition and internal collaboration is represented graphically in Figure 1. This figure illustrates the concept that the two management approaches tend to be mutually exclusive the closer the approaches are positioned to the extremities (Gilbert \& Sutherland, 2013).

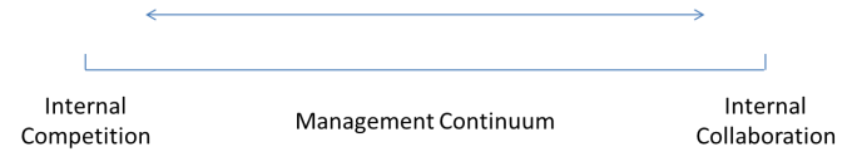

\section{Figure 1: The management continuum model}

Combinations of internal competition and internal collaboration could therefore range from solely internal competition, through an equal combination of both internal competition and internal collaboration, to solely internal collaboration. This approach shows an "either/or" mindset. Alternatively the management dilemma could be graphically represented as depicted below in Error! Reference source not found.. The two-by-two grid illustrates combinations of varying levels of both forces. This model, developed for this study, in contrast with Figure 1, demonstrates the possibility of simultaneously achieving for example high levels of both collaboration and competition or low levels of collaboration and competition. This approach shows a "both/and" mindset. 


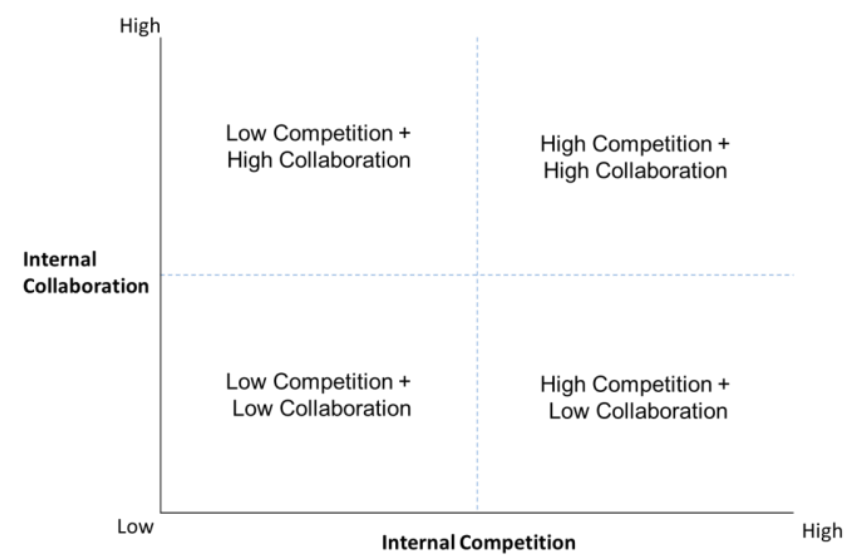

Figure 2: The management paradox model

\section{Social interdependence theory}

According to social interdependence theory (Deutsch, 1949), the structure of interdependencies between people determines the degree of collaborative or competitive interaction between them. Typically, social interdependencies exist when an individual or group's outcomes are affected by the actions of others (Deutsch, 1949; Tjosvold, Johnson, Johnson \& Sun, 2003 and 2006). Positive interdependencies in organisations exist when the goals of two parties are positively correlated while negative interdependencies exist when the attainment of one party's goals prevents a second party from attaining their goals. Positive interdependencies induce collaborative interactions while negative interdependencies induce competitive interactions.

\section{Competition}

Deutsch (1949:130) defines competition as the act of "endeavouring to gain what another is endeavouring to gain at the same time". Khoja (2008) defines internal competition as the rivalry between individuals and business units within an organisation for markets, technologies and organisational resources. Birkinshaw and Lingbald (2005) describe internal competition as the extent of overlap within an organisation between products produced, markets served and business capabilities. Internal competition can result in constructive organisational outcomes. These include increased employee effort to achieve, motivation to take on challenging projects, task effectiveness and the development of strong positive relationships with fellow employees (Tjosvold et al., 2006). Khoja (2008) says that the benefits of internal competition include active experimentation, flexibility to cope with rapid market change, enabling higher levels of innovation and performance across the organisation. He states that the allocation of rewards based on outcomes signals what to focus on and this leads to increased levels of organisation performance.

Various authors (Birkinshaw, 2001; Beersma, Hollenbreck, Humphrey, Moon, Conlon \& Ilgen, 2003; Enns \& Rotundo, 2012; Bittner \& Heidermeier, 2013) highlight the negative impact of competition. These negative outcomes include high levels of employee anxiety, lower productivity, lack of motivation by those who believe they have no chance of winning, increased levels of aggression in those seeking to win at all costs, withholding of information and unethical behaviour (Tjosvold et al., 2006; Birkinshaw, 2001, Enns \& Rotundo, 2012; Mudrack, Bloodgood \& Turnley, 2012). Competing individuals or teams tend to place their own goals above those of the larger organisation and the gains of one are often at the expense of others (Deutsch, 1949; Beersma et al., 2003). Bittner \& Heidermeier (2013) contradict Khoja (2008) arguing that competition leads to a narrower range of attention, which ultimately diminishes creativity. Competition can therefore result in either constructive or destructive outcomes.

Tjosvold et al. (2003) argue that competition within an organisation is more likely when the criteria for winning are clear and enforced. They found the more positive the relationships between members of an organisation were, the more constructive the competition tended to be. Chang and Chen (2012) highlight that the stronger the extrinsic pressure to compete the more destructive the outcomes. Moon, Quigley and Carson Marr (2012:117) say the need to compete is driven by "a belief that the world is a challenging place where limited resources...make for conditions that create winners and losers."

\section{Collaboration}

Beyerlein and Harris (2004) identify three characteristics of collaborative environments; individuals work together toward a shared goal, completing work is dependent on purposeful relationships and individuals are committed to each other's success. In internally collaborative environments, resources are shared thereby lowering costs (Libby \& Thorne, 2009). Collaborative organisations are characterised by having a common identity, centralised integrative configurations, with control practices and incentive systems that reward organisational performance as opposed to individual or business unit performance (Houston et al., 2001 and Birkinshaw, 2001). In this study, the terms collaboration and cooperation are used synonymously.

The consensus is that collaboration promotes trust, cohesiveness and supportive behaviour amongst team members and knowledge sharing, which in turn promotes organisational performance (Beersma et al., 2003; Tsai, 2002; Lou et al., 2006)). Van den Bossche, Gijselaers, Segers and Kirschner (2006) note that collaboration results in teams building a shared understanding of a task, distributing responsibility across members and sharing expertise, thus lowering costs. Bittner and Heidemeier (2013) suggest that individuals in a collaborative environment show a broader range of attention, having a tendency to see relationships between concepts which results in high levels of creativity. Moon et al. (2012) propose that collaboration with autonomy is critical for innovation.

However, in an internally collaborative environment, it can be difficult to distinguish individual performance and the 
possibility of individuals "shirking" responsibility becomes prevalent (Loch, Huberman \& Stout, 2000). This has been recognised as the key source for resisting team based structures in organisations (Loch et al., 2000; Beersma et al., 2003; Ross, Rausch \& Canada, 2003). Beyerlein, Freedman, McGee and Moran (2003) purport that collaborative activities can sometimes be characterised by chaos or situations where the same decisions are being made repetitively because of group think. These negative outcomes of collaborative processes will result in sub-optimal business results.

\section{Factors contributing to collaborative or competitive environments}

Literature identifies various factors that influence the adoption of collaborative and/or competitive practices.

Goals: In his theory of cooperation and competition, Deutsch (1949), argued that an individual's belief about the interrelated nature of their goals with others determines how they interact with each other. Ferguson (2000) emphasises that goals form the basis of motivation, team dynamics and direction. Podsakoff, MacKenzie, and Bommer (1996) emphasised the importance of leaders fostering a common vision of organisational goals. Tjosvold et al. (2003) proposed that when a situation is structured competitively, goal achievement is negatively correlated between individuals or teams. When situations are structured cooperatively, goal achievement is positively correlated between individuals or teams as they perceive that they can fulfil their goals only if others reach their goals. Ferguson (2007) describes horizontal goals that strive for contribution towards team performance. Vertical goals seek to set individuals apart, with rewards resulting in superior status for the individual, resulting in a more competitive environment.

Rewards: Individuals placed in competitive reward structures may be inclined to deter the progress of others in an effort to gain personal advantage (Enns \& Rotundo, 2012). Collaborative rewards are ideal for team performance where there are high levels of interdependence between individuals' responsibilities. In comparison, competitive reward structures are considered more suitable when there are low levels of performance interdependency (Ross et al., 2003; Beersma et al., 2003; Houston et al., 2001). Competitive systems reward individuals and emphasise performance differences between team members (Beersma et al., 2003).

Performance Management: refers to a set of activities that are utilised by an organisation to enhance individual and organisational performance (Biron, Farndale \& Paauwe, 2011 and DeNisi, 2000). Performance measurement, one element of performance management, and the corresponding rewards and incentives directly influence the behaviour of employees (Sprinkle, 2003). Biron et al. (2011) argue that performance management systems signal the required behaviours of employees. Lee and Yang (2011) describing cause-and-effect find that managers drive either collaboration or competition by how they define objectives and outcomes and connecting them to incentives with performance measures.
Combinations of Competition and Collaboration: The literature has placed a growing emphasis on simultaneous cooperation and competition between organisations in an industry as a strategy for competitive advantage (Dagnino Castaldo, LeRoy \& Yami, 2009). This is referred to as coopetition and exists when two or more competing organisations cooperate to create a larger business market and then simultaneously compete for share in that market (Nalebuff \& Brandenburger, 1996). There have been a few studies on coopetition within organisations (Tsai; 2002; Luo et al., 2006) but these have focused on knowledge sharing as the primary outcome. In changing environments team structures may evolve from competition to collaboration and vice versa (Johnson, Hollenbeck, Humphrey, Ilgen, Jundt and Meyer, 2006). They introduce the concept of "cutthroat cooperation" to describe the phenomenon where teams move from competitive environments to where collaboration is required.

\section{Research aim and questions}

The literature highlights internal competition and internal collaboration as separate management approaches (Khoja, 2009; Beersma et al., 2003; Humphrey et al., 2003; Birkinshaw, 2001; Houston et al., 2001). There is no consensus on how to manage these seemingly paradoxical management approaches within an organisation in order to drive organisational performance. This study seeks to provide a framework that will help clarify the components of the dilemma by answering the following research questions.

Research Question 1: What are the key factors that drive internal competition and what are its outcomes?

Research Question 2: What are the key factors that drive internal collaboration and what are its outcomes?

Research Question 3: How does the level of internal collaboration or internal competition vary between executives and non-executives?

Research Question 4: Are managers able to simultaneously combine internally collaborative and competitive approaches to improve organisational performance sustainably?

\section{Research methodology}

As there is no consensus in the literature on how to manage the dilemma of internal competition and internal collaboration this study was deemed to be exploratory. Leedy \& Ormrod (2001:101) state that an exploratory study is a useful technique "to answer questions about the complex nature of phenomena, often describing and understanding the phenomena from the participants' point of view".

The research consisted of a series of semi-structured in-depth interviews with senior executives in one large South African manufacturing organisation, which employs more than 9,000 people in seven manufacturing plants and 40 distribution depots. In the early 1980's with the absence of external competition senior management encouraged internal 
competition between manufacturing plants, regional depots and brand marketing teams to ensure that the business units remained efficient and continued to strive for growth. Since 2007, the organisation has been facing growing external competition and senior management has been motivating for increased collaboration between business units. The tension between the two approaches is currently being explored in the organisation. This made an ideal environment to explore the dilemma in a case. Saunders \& Lewis (2012) state that the case approach is a suitable research methodology when trying to understand why managers make decisions in a certain manner.

An interview guide with open-ended questions was used to ensure both consistency of questioning and valid answers (Zikmund, 2003). It included a standardised introductory statement explaining the purpose of the research and the major constructs. Trial interviews were conducted with three managers to test the viability of the questions. A number of changes were made.

As is common in exploratory research, non-probability sampling techniques were used (Saunders \& Lewis, 2012). The business areas accessed for this study were marketing, sales, manufacturing, supply chain and human resource development. A quota sample of a business area director, two general managers and one senior line manager were interviewed in each of the five areas. These executives were positioned in the organisation such that their locus of control influenced the level of internal competition or collaboration within their business unit and between business units.

Interviewees were encouraged to talk openly and widely about the research themes. The average length of each interview was 45 minutes. Probing techniques were used to extract additional information. The order in which the themes were covered and the questions asked varied from interview to interview. All interviews were recorded and transcribed. The transcripts were loaded on the qualitative analysis tool, ATLAS/ti which facilitates the systematic storage, retrieval, coding and enumerating the data into relevant themes. This assisted in removing researcher bias from the qualitative analysis (Zikmund, 2003).

Limitations of this study. The use of executives from one company means that the findings cannot be generalised across all organisations and all levels of staff. The company's recruitment strategy is specifically biased towards individuals who fit a strong achievement driven profile. Such individuals are inclined to enjoy competition. This may bias the findings.

\section{Results}

Research Question 1: What are the key factors that drive internal competition and what are its outcomes?

The constructs that emerged from the qualitative analysis discussed above led to the identification of the key constructs and their frequency of mention. Eleven factors were highlighted by the interviewees as driving the adoption of internal competition.

Table 1: Factors driving the adoption of internal competition

\begin{tabular}{l|l|c}
\hline Ranking & $\begin{array}{l}\text { Factors Driving the Adoption of } \\
\text { Internal Competition }\end{array}$ & $\begin{array}{l}\text { Number of } \\
\text { Respondents }\end{array}$ \\
\hline 1 & Performance Measures & 17 \\
\hline 2 & $\begin{array}{l}\text { Employee Rewards (performance } \\
\text { based incentives) }\end{array}$ & 17 \\
\hline 3 & Employee Personality & 13 \\
\hline 4 & $\begin{array}{l}\text { Employee Recognition (of work } \\
\text { well done) }\end{array}$ & 10 \\
\hline 5 & External Market Structure & 10 \\
\hline 6 & $\begin{array}{l}\text { Leadership (behaviour and } \\
\text { decision making) }\end{array}$ & 10 \\
\hline 8 & Performance Ranking & 7 \\
\hline 9 & $\begin{array}{l}\text { Goals (targeted business } \\
\text { outcomes) }\end{array}$ & 7 \\
\hline 10 & Organisational Structure & 3 \\
\hline 11 & Organisational Culture & \\
\hline
\end{tabular}

Seventeen respondents identified both performance measures and employee rewards and ten respondents identified employee recognition and performance ranking as the key driving factors for internal competition to be prevalent. Respondents supported this by stating “...what we reward, what we recognize - that's what drives [internal] competition." and "If you set up your measurement criteria where you benchmarking ranks employees against each other. This will result in internal competition." These factors can be grouped together as they are all elements of performance management systems (Roberts, 2001). This supports to the work of Biron et al. (2011) and Lee and Yang (2011) who show that performance management systems provide organisational signals that influence employees' behaviour and outcomes.

Employee personality was the second most mentioned factor driving the adoption of internal competition. One interviewee stated "If you employ people [with] high aspiration...ultimately they have to feel that they have achieved better than their peer group. " This factor speaks to the innate competitive personality trait that influences how some individuals respond to competition shown in the trait competitiveness studies conducted by Mudrack et al. (2012) and Fletcher and Nusbaum (2008).

Leadership behaviour was acknowledged by ten respondents as being pivotal in choosing and driving internal competition. One interviewee said, "As a leader, you have to direct the [internal] competition in areas that require it. Therefore you need to define what areas you want to compete [internally] in..." This finding is consistent with the work of Podsakoff et 
al. (1996) and Pillai and Williams (2004) who emphasised the leaders' influence by role modelling what is deemed to be appropriate behaviours. Their communications, decisions and behaviour can drive the adoption of internal competition.

Ten respondents identified the external market structure as driving the adoption of internal competition. In the context of this case study, this refers to the lack of strong competitors in the market. In market dominant organisations, the potential exists for its performance and efficiency to deteriorate. In such a market, it is proposed that internal competition becomes a viable management approach to drive and sustain performance in the organisation. One executive said, "... when you are in an environment where not-great work is being done then you're comparing yourselves to the tallest midget" and another said that by adopting internal competition one can "... raise standards in the absence of a credible competitor." No references to the external market structure were found in the literature.

\section{Benefits of competition}

While some interviewees had difficulty identifying positive outcomes for internal competition, a total of seven benefits were acknowledged.

\section{Table 2: Benefits of internal competition}

\begin{tabular}{l|l|l}
\hline Ranking & Benefits of Internal Competition & $\begin{array}{l}\text { Number of } \\
\text { Respondents }\end{array}$ \\
\hline 1 & $\begin{array}{l}\text { Continuous Incremental } \\
\text { Improvement }\end{array}$ & 9 \\
\hline 2 & Increased Performance & 9 \\
\hline 3 & Employee Motivation & 8 \\
\hline 4 & Efficiency & 4 \\
\hline 5 & Speed & 3 \\
\hline 6 & Collaboration & 3 \\
\hline 7 & Innovation & 3 \\
\hline
\end{tabular}

Nine respondents identified continuous incremental improvements and increased performance as the most noteworthy benefits of internal competition. As employees strive to better their current performance levels against their peers, incremental improvements in efficiency and performance are gained for both the individual and the organisation. One manager observed "It [internal competition] is constantly lifting the bar, constantly striving for a better organisation - a better way of doing things, being both more effective and more efficient." This concurs with the findings of Tjosvold et al. (2003) who found that constructive internal competition drives increased performance levels.

Employee motivation as a positive outcome of internal competition was supported by eight interviewees. One said "[Internal] competition is probably a way of motivating people to higher standards, by getting individuals to challenge themselves or outperform each other." Tjosvold et al. (2006), Chang and Chen (2012) and Moon et al. (2012) agree that some individuals prefer to compete and are driven to do so by their own personal preference.

It is of particular interest to this study that three executives noted that internal competition can lead to greater cooperation.

\section{Drawbacks of Internal Competition}

Respondents identified swiftly and confidently the negative aspects of internal competition.

\section{Table 3: Drawbacks of internal competition}

\begin{tabular}{l|l|c}
\hline Ranking & \multicolumn{1}{|c}{$\begin{array}{c}\text { Drawbacks of Internal } \\
\text { Competition }\end{array}$} & $\begin{array}{c}\text { Number of } \\
\text { Respondents }\end{array}$ \\
\hline 1 & $\begin{array}{l}\text { Limited Sharing of Knowledge and } \\
\text { Resources }\end{array}$ & 14 \\
\hline 2 & Unethical Behaviour & 10 \\
\hline 3 & $\begin{array}{l}\text { Duplication of Effort and } \\
\text { Resources }\end{array}$ & 8 \\
\hline 4 & Employee Disengagement & 4 \\
\hline 5 & $\begin{array}{l}\text { Inward Focus (as opposed to being } \\
\text { Market Focused) }\end{array}$ & 4 \\
\hline 6 & $\begin{array}{l}\text { Friction (between individuals and } \\
\text { teams) }\end{array}$ & 3 \\
\hline
\end{tabular}

Fourteen of the interviewees mentioned that high levels of internal competition can result in limited sharing of explicit and tactic knowledge between teams and individuals as employees seek to preserve what they perceive as their competitive edge. Senior managers can restrict the career progression of crucial employees for this same reason. This hoarding behaviour then leads to duplication of effort and resources within the organisation which increases costs and erodes business value.

Ten respondents in this study identified unethical behaviour as another negative outcome of high internal competition. It can take many forms such as "People deliberately going out of their way to sabotage their peers because they want to win." Other examples include fraudulent reporting, purposefully compromising quality to increase production volumes and backstabbing.

These research findings support Birkinshaw (2001) who highlights the resulting duplication of costs from overlap within the organisation because of internal competition. Beersma et al. (2003) observed the gains of one individual are often at the expense of others and that individuals in competitive environments tend to hoard valuable information. Enns and Rotundo (2012) noted that individuals in competitive reward structures are inclined to deter the progress of others to gain personal advantage. Tsai (2002) and Luo et al. (2006) write of the problems of knowledge sharing under competitive conditions. 
Figure 3 illustrates a summary of the research findings pertaining to research question 1 .

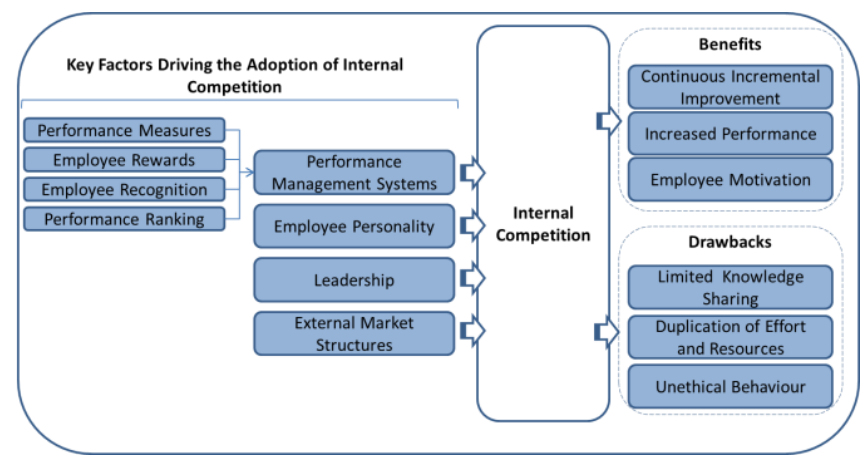

Figure 3: Findings on internal competition

Research Question 2: What are the key factors that drive internal collaboration and what are its outcomes?

Nine factors that drive an internally collaborative approach were highlighted by the interviewees.

Table 4: Ranking of factors driving the adoption of internal collaboration

\begin{tabular}{l|l|c}
\hline Ranking & $\begin{array}{l}\text { Factors Driving the Adoption of } \\
\text { Internal Collaboration }\end{array}$ & $\begin{array}{l}\text { Number of } \\
\text { Respondents }\end{array}$ \\
\hline 1 & $\begin{array}{l}\text { Leadership (behaviour and } \\
\text { decisions) }\end{array}$ & 14 \\
\hline 2 & $\begin{array}{l}\text { Goals (targeted business } \\
\text { outcomes) }\end{array}$ & 10 \\
\hline 3 & Performance Measures & 10 \\
\hline 4 & Organisational Structure & 10 \\
\hline 5 & Business Strategy & 9 \\
\hline 6 & Recognition & 9 \\
\hline 7 & Shared Vision & 7 \\
\hline 8 & Employee Personality & 6 \\
\hline 9 & Reward & \\
\hline
\end{tabular}

Leadership behaviour and decisions were ranked as the most significant factor driving the adoption of internal collaboration. Fourteen managers supported this view with one saying "Leadership must make it [internal collaboration] happen - through processes, through making resources and time available, through driving behaviour." By exhibiting internally collaborative behaviours with their peers, leadership strongly signals to the rest of the organisation that collaborative behaviour and activities are deemed preferable. This finding remains consistent with the work of Podsakoff, et al. (1996) and Pillai and Williams (2004) as mentioned above.

Performance measures and goals were each identified by ten respondents as significant factors driving internal collaboration. One interviewee stated, "You do need to find particular goals around collaboration. They [goals] need to be expressed or to be defined in such a way, that it requires collaboration." The critical importance of goals and performance measures were emphasised by Roberts (2001). When they are defined such that they result in interdependencies across different teams, then internal collaboration is stimulated between employees who must work together to achieve their own success. This supports Deutsch's (1949) and Tjosvold et al. (2006) belief in interrelatedness of goals driving collaboration. Various recent authors (Ferguson, 2007; Libby \& Thorne, 2009; Beersma et al., 2003) agree that how managers set individual, team and organisation goals influences collaboration. Table 1 showed that performance measures also are the main driver of competition. Hence the power of setting objectives is demonstrated in both cases.

Organisational structure and strategy in terms of configuration, processes and systems were perceived to drive collaboration. Centralised organisational structures were deemed to drive collaborative behaviour across the organisation. Ten respondents supported this view with one explaining that the organisation "...has got to have process and purpose and structure to make sure it stays aligned to the overall business objective". Houston et al. (2001) and Birkinshaw (2001) both agree that centralised organisational structures encourage collaboration and integration via control practises and incentive systems that reward organisational performance as opposed to business unit performance.

\section{Benefits of collaboration}

The interviewees noted six benefits of internal collaboration.

Table 1: Benefits of internal collaboration

\begin{tabular}{l|l|c}
\hline Ranking & $\begin{array}{l}\text { Benefits of Internal } \\
\text { Collaboration }\end{array}$ & $\begin{array}{l}\text { Number of } \\
\text { Respondents }\end{array}$ \\
\hline 1 & Knowledge Sharing & 11 \\
\hline 2 & $\begin{array}{l}\text { Accelerated Implementation of } \\
\text { Best Practice }\end{array}$ & 7 \\
\hline 3 & Organisational Cohesion & 7 \\
\hline 4 & Reduced Costs & 5 \\
\hline 5 & Innovation and Creativity & 5 \\
\hline 6 & Effectiveness & 3 \\
\hline
\end{tabular}

An increase in the sharing of knowledge was deemed to be the most significant positive outcome of internal collaboration with eleven respondents supporting this finding. One interviewee emphasised this "The biggest benefit is - if you can get everybody to do what someone is doing well somewhere, it's just a matter of time before we are all great." Knowledge sharing not only takes the form of explicit information but also includes the utilisation of skilled individuals with tacit experiential knowledge across business functions. Van den Bossche et al. (2006), Tsai (2002) and Polenske (2004) also demonstrated that knowledge sharing is an outcome of collaboration. 
The benefit of accelerated best practice implementation was identified by seven respondents. They noted that internal collaboration allows managers to leverage economies of scale and centralise specific resources for the use of the organisation as a whole, thereby reducing the need to duplicate skills and effort across business functions. This results in reduced costs and the efficient use of organisational resources. Five respondents supported this finding, one saying "IIf there is] a breakthrough in one part of the business, I can replicate it and get economy of scale out of that quickly..." In this way managers are able to increase overall organisational efficiency and performance. This research finding is consistent with the work of Libby and Thorne (2009), Houston et al. (2001) and Van den Bossche et al. (2006).

Organisational cohesion was identified by seven respondents as being a key benefit of internal collaboration. This is a sense of increased interconnectedness between employees and teams within the organisation. One interviewee said "I think it [internal collaboration] creates a sense of belonging and as humans we like to belong”. As Beyerlein and Harris (2004) explained, when collaborative work is undertaken, there is a sense of shared purpose and direction which has a positive spin off on organisational performance.

Innovation was identified by five respondents as another significant benefit of internal collaboration. The marketing director emphasised this by stating "I am a strong believer in collaboration because we create things. In order to come up with an idea, you need multiple people to work on that idea." This research finding is consistent with the work of Bittner and Heidemeier (2013) and Moon et al. (2012). This finding however contradicts the work of Khoja (2008) and Birkinshaw (2001), who both insist that internal competition drives product innovation.

\section{Table 6: Drawbacks of internal collaboration}

Despite the benefits of collaboration interviewees pointed out four drawbacks of collaboration.

\begin{tabular}{l|l|c}
\hline Ranking & $\begin{array}{l}\text { Drawbacks of Internal } \\
\text { Collaboration }\end{array}$ & $\begin{array}{l}\text { Number of } \\
\text { Respondents }\end{array}$ \\
\hline 1 & Decreased Efficiency & 6 \\
\hline 2 & Groupthink & 5 \\
\hline 3 & $\begin{array}{l}\text { Limited } \\
\text { Ownership/Responsibility }\end{array}$ & 4 \\
\hline 4 & $\begin{array}{l}\text { Complacency in the } \\
\text { Workplace }\end{array}$ \\
\hline
\end{tabular}

Six managers referred to the potential inefficiencies caused by protracted decision making processes in high levels of collaboration. As one senior manager stated, "The drawback is if you don't do that [structure the collaboration] you are going to have lots of activity but no outcome so you can really drown the business in non-value adding collaboration activities." This finding is consistent with the work of
Beyerlein et al. (2003), which highlighted the potential for disruptive chaos in collaborative processes. Loch et al. (2000) and Beersma et al. (2003) also highlighted the concomitant risk of employee shirking which results in lower overall efficiency, which erodes business performance and value.

Groupthink was the other significant drawback highlighted by five respondents, with one manager saying, "I think if you become too collaborative you get group think - people don't challenge each other. It may lead to [choosing] the path of least resistance because you believe you have to collaborate." Groupthink occurs when group of individuals are more driven to achieve a level of consensus rather than in exploring the best alternative or decision. Beyerlein et al. (2003) highlight the potential for collaborative process to result in decisions that are made again and again.

Figure 4 illustrates a summary of the research findings pertaining to research question 2 .

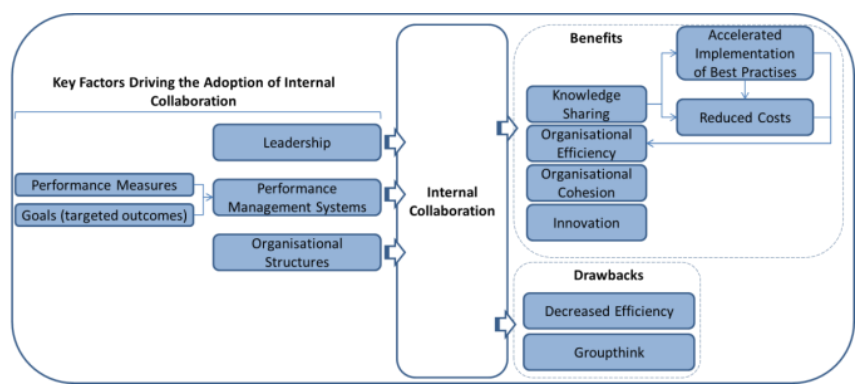

Figure 4: Findings for internal collaboration

Research Question 3: How does the level of internal collaboration or internal competition vary between executives versus non-executives?

The interviewees were asked to evaluate the amount of internal competition or internal collaboration at executive and non-executive levels. They were asked to select from four managerial approaches. The findings show a strong pattern in how the intensity of competition or collaboration differs between the two levels.

Table 7: Competition and collaboration at different levels of the organisation

\begin{tabular}{|c|c|c|c|c|}
\hline \multirow[b]{2}{*}{$\begin{array}{c}\text { Organisation } \\
\text { Level }\end{array}$} & \multicolumn{4}{|c|}{ Number of Respondents } \\
\hline & 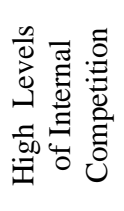 & 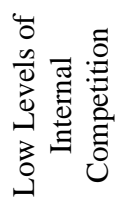 & 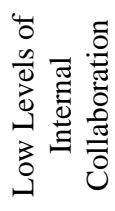 & 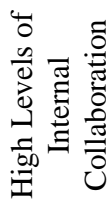 \\
\hline Executives & 4 & 3 & 1 & 12 \\
\hline $\begin{array}{l}\text { Non- } \\
\text { executives }\end{array}$ & 14 & 1 & 2 & 3 \\
\hline
\end{tabular}


Twelve interviewees maintained that as the level of seniority increased, the level of internal collaboration also increased. As one respondent succinctly stated, "I suppose the higher you go up from a leadership point of view, the more important collaboration becomes". At senior management levels the business goals are usually overarching across teams and business units. Success is seldom determined by only business aspects within a senior managers' direct control and hence internal collaboration becomes key to realising their objectives. This result was found to be consistent with Deutsch's (1949) and Tjosvold et al. (2006) theory of interdependence. However, in certain circumstances, executives can demonstrate high levels of internal competition. Seven respondents indicated that they experienced internally competitive behaviour at senior management levels and that this could be attributed to the high value incentives based on divisional performance. As one senior manager stated, "The recognition and the reward outcome, of being seen as the winner the higher you go into an organisation, becomes higher-becomes more of a driver for competition."

Fourteen respondents reasoned that there were higher levels of internal competition at the non-executives level. Nonexecutive roles are often defined to be more task-orientated and generally require low levels of dependency for successful outcomes. One interviewee said "So you want to be best in class with distribution, you want to be best in class in packaging; you want to be best in class in procurement... You maintain strong competition at those levels to ensure that people are striving to be best in class." These findings are once more consistent with Deutsch's seminal (1949) theory and Tjosvold et al. (2006) findings. This finding also supported the work of Tjosvold et al. (2003) who identified task-orientation, extrinsic pressures and intrinsic pressures as motives for engaging in competitive behaviour. These motives are most prevalent at the non-executive levels where work is generally task orientated and promotions are limited resulting in both extrinsic pressures and intrinsic pressures to compete.

Although some variance in responses exists, there was overwhelming evidence supporting the finding that within an organisation, executives are more internally collaborative and non-executives are more internally competitive.

Research Question 4: Are managers able to simultaneously combine internally collaborative and competitive management approaches to improve performance sustainably?

All twenty respondents agreed that it was possible and desirable to achieve a hybrid combination of internal competition and internal collaboration. They indicated which type of combination they believe would result in sustainably high levels of organisational performance.
Table 8: Preferred combinations of internal competition and internal collaboration

\begin{tabular}{c|l|c}
\hline Rank & $\begin{array}{l}\text { Combination of Internal Competition and } \\
\text { Internal Collaboration }\end{array}$ & $\begin{array}{c}\text { Number of } \\
\text { Respondents }\end{array}$ \\
\hline 1 & $\begin{array}{l}\text { High Internal Competition and High Internal } \\
\text { Collaboration }\end{array}$ & 8 \\
\hline 2 & $\begin{array}{l}\text { High Internal Collaboration and Low Internal } \\
\text { Competition }\end{array}$ & 4 \\
\hline 3 & $\begin{array}{l}\text { Either High Internal Collaboration and Low } \\
\text { Internal Competition or High Internal } \\
\text { Competition and Low Internal Collaboration }\end{array}$ & 4 \\
\hline 4 & $\begin{array}{l}\text { Either High Internal Collaboration and High } \\
\text { Internal Competition or High Internal } \\
\text { Collaboration and Low Internal Competition }\end{array}$ & 2 \\
\hline 5 & $\begin{array}{l}\text { Medium Internal Competition and High } \\
\text { Internal Collaboration }\end{array}$ & 1 \\
\hline 6 & $\begin{array}{l}\text { High Internal Competition and Low Internal } \\
\text { Collaboration }\end{array}$ & 1 \\
\hline
\end{tabular}

While most respondents identified a single combination as being optimal for performance, six respondents said there were benefits in positioning different functions across different combinations of internal competition and internal collaborations. Their view on these multiple combinations are described in the table as options 3 and 4 . The table was plotted on a 3 by 2 matrix to display the distribution of respondents' perspectives of optimal combinations in Figure 4. Options A and $\mathrm{B}$ illustrate the views of six respondents who believed that two combinations were equally viable for driving high performance.

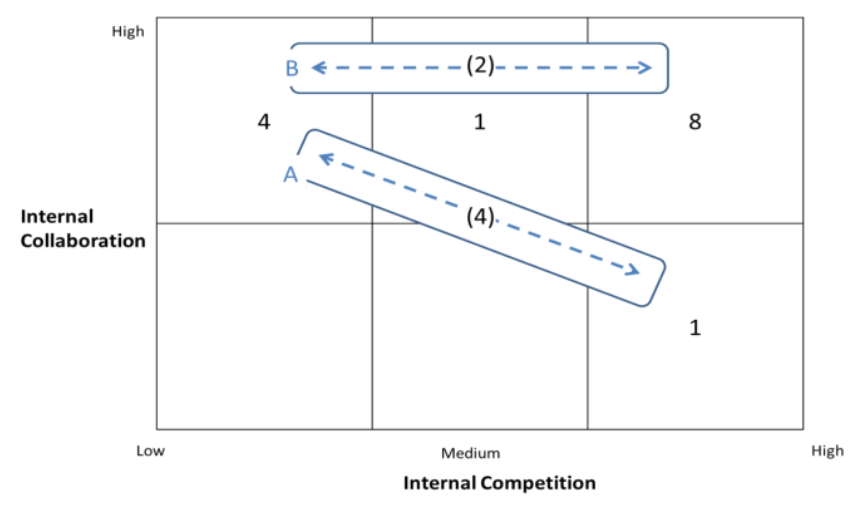

Figure 4: Distribution of preferred hybrid combinations

This clearly shows a preference for high levels of internal collaboration with varying levels for internal competition as the most beneficial combinations for organisational performance. 
High Internal Competition and High Internal Collaboration was the most preferred option. One manager said "In the sales organisation you are so dependent on individual performance that competition really would make a difference in our outputs. Whereas with our staff functions collaboration is also very important because it's about the whole." Whilst another stated "If you compete for the right reasons and [if you're] collaborating with teams, adhering to social systems, process and so on...you do not need to worry about the score card."

High Internal Collaboration and Low Internal Competition was supported by four respondents as more suitable, making comments such as "if the competition side is almost overplayed it can kill the collaboration side, and we've certainly seen evidence of that." And "[It] can become a downward spiral that we've got to be very careful of too much competition; too much of the "dog eat dog", you'll end up destroying the pack."

Either High Internal Collaboration and Low Internal Competition or High Internal Competition and Low Internal Collaboration were proposed by four respondents depending on the business unit structure and scope of the employees' role. They expressed their views as follows: "Collaborative competition or competitive collaboration. I really see that as a technique that can be made to work" and "You have got to choose those points of collaboration carefully - in terms of what is needed versus what is effective and what is not."

Eight interviewees believed that the optimal approach for organisational success was to position the organisation at high levels of internal collaboration and high levels of competition, yet they indicated that they were uncertain if such an option was sustainable over the long term. They thought that tensions between the two approaches at very high levels would engender an awkward pull and push effect, that, together with the natural intrinsic tendency of employees to compete, (Mudrack et al., 2012 and Fletcher \& Nusbaum, 2008) would result in internal competition becoming the dominant force. The negative outcomes of high levels of internal competition would then result in business value being eroded.

While internal competition and internal collaboration appear to be paradoxical and contrary, the results showed that managers felt able to combine the benefits of internal competition and internal collaboration to achieve an optimal balance or "sweet spot". Thus, the two management approaches are not necessarily mutually exclusive but can be simultaneously adopted as a hybrid approach. This finding was supported by all twenty respondents, validating that the best management approach to this dilemma is not one of linear focus on either internal competition or internal collaboration, but rather one where both internal competition and internal collaboration are leveraged simultaneously. They felt that internal collaboration contains essential attributes that contribute to the long-term success of an organisation while internal competition contributes vital elements essential to an organisation's ability to unleash the potential of their employees and hence both are necessary.

The optimal balance or "sweet spot" that managers should strive to achieve between internal competition and internal collaboration is thought to occur at moderate levels of internal competition. The two forces would then reinforce and leverage off each other. This hybrid combination ensures that managers are able to extract the benefits of internal competition and internal collaboration while staving off the negative outcomes associated with these management approaches if used exclusively. Internal competition will focus attention and effort on organisational efficiencies and by driving individual accountability will limit groupthink. Internal collaboration will facilitate knowledge sharing and efficient use of resources in the organisation. As individuals and teams collaborate to achieve common goals the likelihood of unethical behaviour becomes less likely. These research findings are consistent with the literature that emphasises the importance of bridging the horns of a dilemma and moving from the perspective of an either/or approach to a both/and approach (Gilbert \& Sutherland, 2013; Kahane, 2012; Peters, 2012; Yoon \& Chae, 2012 and Smith \& Lewis, 2011). Authors such as Tsai (2002) and Luo et al. (2006) refer to this as coopetition.

In addition to the different preferences per job level as discussed in research question 3 , it is also important to note that the research findings showed distinct preferences for specific combinations between the various business functions. Respondents in the decentralised sales and manufacturing functions were more predisposed towards higher levels of internal competition than the centralised business functions of supply chain, marketing and human resources. This suggests that the dilemma should be adaptively managed within the organisation, with higher levels of internal competition being adopted in decentralised business functions and for non-executive staff and somewhat lower levels of internal competition being adopted in centralised business functions and for executives. This finding is consistent with the work of Houston et al. (2001) and Lou et al. (2006).

\section{Synthesis of research findings}

This study contributes to the broader theory around the complexity of the seemingly conflicting management approaches in driving organisational performance. The first contribution relates to the breadth and span of factors that drive the adoption of internal competition and collaboration. There is significant overlap across certain factors, in that they can drive either internal competition or internal collaboration. In particular, leadership (behaviour and decision making) and performance management systems (which include performance measures, performance rewards, recognition and goals) were identified as having strong influence in driving both approaches. It is therefore crucial to consciously manage how these factors are applied in order to obtain the desired outcome of organisational performance. 
The second contribution of this study relates to the implications of each approach. Internal competition can drive employee motivation and high levels of performance in both the employee and the organisation. Internal collaboration drives organisational efficiencies by enabling knowledge sharing, optimal resource distribution and innovation by leveraging employee diversity. However, very high levels of either approach results in negative outcomes that erode business value. Extremely high levels of sustained internal competition can encourage unethical behaviour, limited knowledge sharing and duplication of effort and resources as employees seek to preserve their competitive edge. High levels of internal collaboration can lead to loss of efficiency as individuals lose their sense of accountability resulting in a sense of complacency as well as groupthink becoming prevalent which can erode innovation. The impact of all these outcomes on organisational performance is significant.

The third contribution of this study relates to the paradoxical nature of competition and collaboration in which they can and should co-exist for optimal organisational performance. The management dilemma is resolved, not in an absolute manner, but rather in defining the most appropriate hybrid combination of the two approaches for any specific situation. The study found that if management is successful in achieving a balance with moderate levels of internal competition and internal collaboration, in a form of internal coopetition, employees will be motivated both intrinsically and extrinsically to strive towards sustainable high performance. Luo et al. (2006) when examining just the marketing functions relationship to the rest of the business found that engaging in more intense and absorbed collaborations across competing functional boundaries can enhance a firm's overall performance.

A framework integrating the findings of this study is presented in Figure 5.

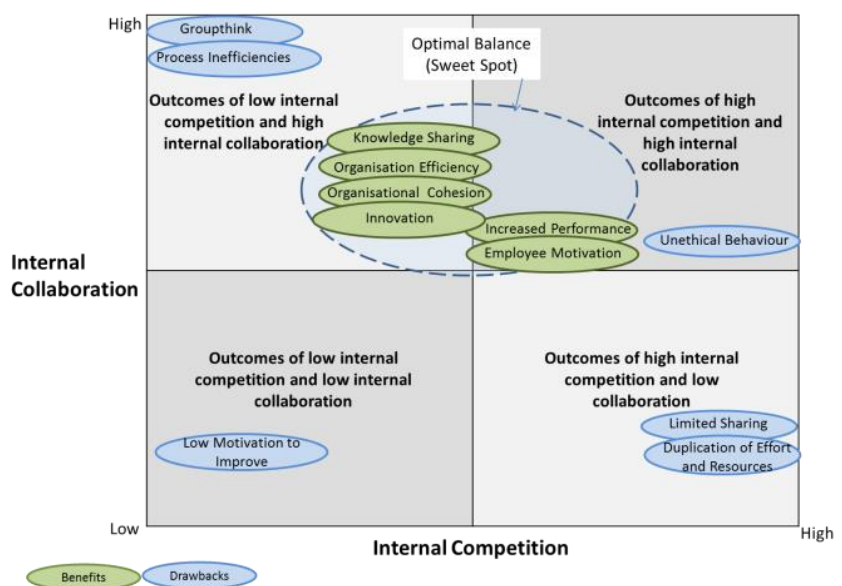

Figure 5: The internal competition and internal collaboration hybrid model

It shows that the optimal balance or "sweet spot" that managers should strive to achieve occurs when managers adopt a hybrid approach that combines moderate levels of internal competition and high levels of internal collaboration.
At these levels, the two forces reinforce and leverage off each other to drive sustainable employee and organisational performance through higher organisational efficiency and innovation whilst simultaneously improving organisational cohesion and knowledge sharing. Managers need to consider the practices, which must be utilised to maintain the optimal balance or sweet spot. These include leadership behaviour and decision-making, setting goals and performance measures, rewards, recognition, employee recruitment profiles and organisational structure. This also requires an understanding of the possibilities and practices of coopetition.

Recommendation for Future Research This research was based on interviews with executives in one organisation. The findings needed to be tested in other types of organisations. Research could be conducted with middle managers who may have a different perspective regarding the dilemma. The management systems and practices that enforce the "sweet spot" need to be empirically identified.

It is hoped that this study contributes to both the study and practice of managing dilemmas and paradoxes in addition to casting more light on the field of collaboration versus completion as potential management levers for encouraging employee and organisational performance.

\section{References}

Andriopoulos, C. \& Lewis, M.W. 2009. 'Exploitation Exploration tensions and organisational ambidexterity: Managing paradoxes of innovation', Organisational Science, 20(4), 696-717.

Beersma, B., Hollenbeck, J.R., Humphrey, S.E., Moon, H., Conlon, D.E. \& Ilgen, D.R. 2003. 'Cooperation, competition, and team performance: Toward a contingency approach', Academy of Management Journal, 46(5), 572-590.

Bengtsson, M., Eriksson, J. \& Wicen, J. 2010. 'Co-opetition dynamics - An outline for further inquiry', Competitiveness Review: An international business Journal, 20(2). 194-214.

Bengtsson, M. \& Kock, S. 2000. "“Coopetition” in business networks - To cooperate and compete simultaneously', Industrial Marketing Management, 29(5), 411-426.

Beyerlein, M.M., Freedman, S., McGee, C. \& Moran, L. 2003. 'The ten principles of collaborative organizations', Journal of Organizational Excellence, 22(2), 51-63.

Beyerlein, M.M. \& Harris, C.L. 2004. Guiding the journey to collaborative work systems: A strategic design workbook. San Francisco, CA: Pfeiffer.

Birkinshaw, J. 2001. 'Strategies for managing internal competition', California Management Review, 44(1), 21-38.

Birkinshaw, J. \& Lingblad, M. 2005. 'Intrafirm competition and charter evolution in the multibusiness firm', Organization Science, 16(6), 674-686.

Biron, M., Farndale, E. \& Paauwe, J. 2011. 'Performance management effectiveness: Lessons from world-leading firms', The International Journal of Human Resource Management, 22(6), 1294-1311. 
Bittner, J.V. \& Heidemeier, H. 2013. 'Competitive mindsets, creativity, and the role of regulatory focus', Thinking Skills and Creativity, 9(August), 59-68

Chang, K.I. \& Chen, H.J. 2012. 'Effects of a rival's perceived motives on constructive competition within organizations: A competitive dynamics perspective', Asian Journal of Social Psychology, 15(3), 167-177.

Chen, M.J. 2008. 'Reconceptualizing the competition-cooperation relationship: A transparadox perspective', Journal of Management Inquiry. 17, 288-304.

Chin, K.S., Chan, B.L. \& Lam, P.K. 2008. 'Identifying and prioritizing critical success factors for coopetition strategy', Industrial Management and Data Systems, 108(4), 437-454

Dagnino, P., Castaldo, S., LeRoy, F. \& Yami, S. 2009. Coopetition strategy: Winning strategies for the 21st century. Cheltenham: Edward Elgar.

DeNisi, A.S. 2000. Performance appraisal and performance management: A multilevel analysis. In K.J. Klien and S. Katozlowski (Eds.), Multilevel theory, research and methods in organizations (pp.121-156). San Francisco, CA: Jossey-Bass.

Deutsch, M. 1949. 'A theory of cooperation and competition', Human Relations, 2(1), 129-152.

DuBois, S. 2012. 'Is internal competition at work worth all the trouble?', Fortune. January ( $25^{\text {th }}$ Edition) sourced online.

Enns, J.R. \& Rotundo, M. 2012. 'When competition turns ugly: Collective injustice, workgroup identification and counterproductive work behavior', Human Performance, 25(1), $26-51$

Farjoun, M. 2010. 'Beyond dualism: Stability and change as a duality', Academy of Management Review, 35(2), 202-225.

Ferguson, E.D. 2000. 'Individual psychology is ahead of its time', The Journal of Individual Psychology, 56(1), 14-20.

Ferguson, E.D. 2007. 'Work relations and work effectiveness: Goal identification and social interest can be learned', The Journal of Individual Psychology, 63(1), 110-117.

Fletcher, T.D. \& Nusbaum, D.N. 2008. 'Trait competitiveness as a composite variable: Linkages with facets of the big-five', Personality and Individual Differences, 45(4), 312-317.

Gilbert, G. \& Sutherland, M. 2013. 'The paradox of managing autonomy and control', South African Journal of Business Management, 44(1), 15-27.

Houston, M.B., Walker, B.A., Hutt, M.D. \& Reingen, P.H. 2001. 'Cross-unit competition for a market charter: The enduring influence of structure', Journal of Marketing, 65(2), 19-34.

Hulsmann, M. \& Berry, A. 2004. Strategic management dilemmas: Its necessity in a world of diversity and change, SAM/IFSAM VIIth world congress on management in a world of diversity and change. (pp1-43). Gotesborg.

Johnson, M.D., Hollenbeck, J.R., Humphrey, S.E., Ilgen, D.R., Jundt, D. \& Meyer, C.J. 2006. 'Cutthroat cooperation: Asymmetrical adaptation to changes in team rewards structures', Academy of Management, 49(1), 103-119.
Johnson, J.D. 2012. 'Knowledge networks: Dilemmas and paradoxes', International Journal of Information Management, 32, 347-353.

Kahane, A. 2010. Power and love: A theory and practice of social change. San Francisco, CA: Berret-Koehler Publishers.

Kahane, A. 2012. Transformative scenario planning: Working together to change the future. San Francisco, CA: Berret-Koehler Publishers.

Khoja, F. 2008. 'Is sibling rivalry good or bad for high technology organizations?', Journal of High Technology Management Research, 19(1), 11-20.

Lee, C.-L. \& Yang, H.-J. 2011. 'Organization structure, competition and performance measurement systems and their joint effects on performance', Management Accounting Research, 22, 84-104.

Leedy, P.D. \& Ormrod, J.E. 2001: Practical research: Planning and design. New Jersey: Merill Prentice Hall.

Libby, T. \& Thorne, L. 2009. 'The influence of incentive structure on group performance in assembly lines and teams', Behavioural Research in Accounting, 21(2), 57-72.

Loch, C.H., Huberman, B.A. \& Stout, S. 2000. 'Status competition and performance in work groups', Journal of Economic Behaviour and Organization, 43(1), 35-55.

Luo,Y., Slotegraf, R.J. \& Pan, X. 2006. 'Cross functional "coopetition": The simultaneous role of co-operation and competition within firms', Journal of Marketing, 70(April), 67-80.

Luscher, L.S. \& Lewis, M.W. 2008. 'Organisational change and managerial sensemaking: Working through paradox', Academy of Management Journal, 51(2), 221-240.

Moon, H., Quigley, N.R. \& Marr, J.C. 2012. 'How interpersonal motives explain the influence of organizational culture on organizational productivity, creativity, and adaptation', Organizational Psychology Review, 2(2), 109-128.

Mudrack, P.E., Bloodgood, J.M. \& Turnley, W.H. 2012. 'Some ethical implications of individual competitiveness', Journal of Business Ethics, 108(3), 347-359.

Nasim, S. \& Sushil. 2011. 'Revisiting organisational change: Exploring the paradox of managing continuity and change', Journal of Change Management, 11(2), 185-206.

Nalebuff, B.J. \& Brandenburger, A. 1996. Co-opetition. London: Harper Collins Business.

Peters, L. 2012. 'The rhythm of leading change: Living with paradox', Journal of Management Inquiry, 21(4), 405-411.

Pillai, R. \& Williams, E.A. 2004. 'Transformational leadership, self-efficacy, group cohesiveness, commitment, and performance', Journal of Organizational Change Management, 17(2), 144-159.

Podsakoff, P.M., MacKenzie, S.B. \& Bommer, W.H. 1996. 'Transformational leader behaviors and substitutes for leadership as determinants of employee satisfaction, commitment, trust, and organizational citizenship behaviors', Journal of Management, 22(2), 259-98 
Polenske, K. 2004. 'Competition, collaboration and cooperation: An uneasy triangle in networks of firms and regions', Regional Studies, 38(9), 1029-1043.

Rijamampianina, R. \& Carmichael, T. 2005. 'A framework for effective cross-cultural co-opetition between organisations', Problems and Perspectives in Management, 3(4), 92-103.

Robbins, S., Judge, T.A., Odendaal, A. \& Roodt, G. 2009. Organisational behaviour: Global and Southern African perspectives. Johannesburg: Pearson Education.

Roberts, I. 2001. Rewards and performance management. In I. Beardwell and L. Holden (Eds.), Human resource management: A contemporary approach. 3rd edition. Edinburgh: Pearson. pp.506558.

Ross, S.R., Rausch, M.K. \& Canada, K.E. 2003. 'Competition and cooperation in the five-factor model: Individual differences in achievement orientation', The Journal of Psychology, 137(4), 323337.

Saunders, M. \& Lewis, P. 2012. Doing research in business and management: An essential guide to planning your project. London: Pearson Education Limited.

Serretta, H., Bendixen, M. \& Sutherland, M. 2009. 'Core corporate governance dilemmas facing boards: A South African perspective', South African Journal of Economic and Management Sciences, 12(2), 194-208.

Smith, W.K. \& Lewis, M.W. 2011. 'Toward a theory of paradox: A dynamic equilibrium model of organizing', Academy of Management Review, 36(2), 381-403.

Sprinkle, G.B. 2003. 'Perspectives on experimental research in managerial accounting', Accounting, Organizations and Society, 28(2-3), 287-318.

Tjosvold, D., Johnson, D.W., Johnson, R.T. \& Sun, H. 2003. 'Can interpersonal competition be constructive within an organisation?', The Journal of Psychology, 137(1), 63-84.

Tjosvold, D., Johnson, D.W., Johnson, R.T. \& Sun, H. 2006. 'Competitive motives and strategies: Understanding constructive competition', Group Dynamics: Theory, Research and Practice, 10, 87-99.

Tsai,W. 2002. 'Social structures of "coopetition" within a multinational organization: Co-ordination, competition and organizational knowledge sharing', Organizational Science, 13(2), 179-190.

Van den Bossche, P., Gijselaers, W.H., Segers, M. \& Kirschner, P.A. 2006. 'Social and cognitive factors driving teamwork in collaborative learning environments, team learning beliefs and behaviors', Small Group Research, 37(5), 490-521.

Yoon, S.J. \& Chae, Y.J. 2012. 'Management of paradox: A comparative study of management practices in Korean and Japanese firms', The International Journal of Human Resource Management, 23(17), 3501-3521.

Zikmund, W.G. 2003. Business research methods. 7th edition. Cincinnati, OH: South-Western Cengage Learning. 